\title{
Influencia de la política pública de transporte aéreo en la dinámica del flujo turístico. El caso de Colombia
}

\author{
Oscar Díaz Olariaga* \\ Universidad Santo Tomás (Colombia)
}

\begin{abstract}
Resumen: El presente artículo, de revisión, analiza la influencia e impacto de las políticas públicas del transporte aéreo en la dinámica del flujo turístico vía aérea en Colombia. Siguiendo la tendencia mundial, en materia de liberalización de la industria de la aviación, Colombia ha diseñado e implementando, de forma ininterrumpida desde hace dos décadas y media (y aún en curso), una extensa batería de políticas públicas especialmente estructuradas para el sector aéreo. Como resultado de estas políticas, el tráfico de pasajeros aéreos y muy especialmente de aquellos que viajan por turismo, tanto entrantes (extranjeros) como salientes (colombianos), se ha disparado en la última década mostrando indicadores de muy alto crecimiento.
\end{abstract}

Palabras Clave: Transporte aéreo; Política pública; Liberalización; turismo; Colombia.

Influence of public sector policies on air transport and the dynamics of tourist flows. The case of Colombia

Abstract: This article analyses the influence and impact of public policies of air transport on the tourism flow dynamics in Colombia. Following the global trend of deregulation of air transport carriers, Colombia has uninterruptedly designed and implemented an extensive array of specially structured public policies for the air transport sector for over two and a half decades (ongoing process). As a result of these policies, air passenger traffic both foreign (incoming) and Colombian (outgoing) tourists, has gradually increased, displaying high-level indication of growth.

Keywords: Air transport; Deregulation; public policy; Tourism; Colombia.

\section{Introducción}

La relación entre transporte aéreo (o aviación, que en el presente estudio se utilizará de forma indistinta) y turismo ha cobrado una gran relevancia en las últimas tres décadas (Bieger y Wittmer, 2006; Barrett, 2008; Chung y Whang, 2011; Graham et al., 2008; Sengür et al., 2014; Graham y Dobruszkes, 2019). En la actualidad más de la mitad de los turistas internacionales eligen el transporte aéreo para viajar entre destinos, especialmente para distancias largas o muy largas (Alsumairi y Tsui, 2017). Una de las principales causas de este desarrollo es, sin lugar a dudas, la liberalización de la industria del transporte aéreo, situación que ha jugado un papel esencial en la estimulación del turismo (Zajac, 2016; Dobruszkes et al., 2016; Warnock-Smith y Morrell, 2008; Warnock-Smith y O'Connell, 2011; Yarde y Jonsson, 2016). Ahora bien, la liberación del transporte aéreo se ha producido de forma escalonada a escala mundial, es decir a diferentes velocidades, incluso hoy en día aún está en curso. Por ello, los países suelen tratar de evaluar, muy cuidadosamente, los beneficios y costos de la liberalización del mercado de la aviación para su economía y su industria turística (Duval, 2008). En sus políticas liberalizadoras del transporte aéreo los países intentan siempre buscar un equilibrio entre beneficiar (o al menos no perjudicar) a los operadores aéreos locales y a la vez potenciar el turismo nacional (Forsyth, 2006, 2010). La positiva experiencia en varios países y regiones del mundo ha conducido a que otros muchos países hayan tomado nota del efecto significativo de la liberalización de la aviación sobre la industria

Universidad Santo Tomás (Colombia); E-mail: OscarDiazOlariaga@usantotomas.edu.co; https://orcid.org/0000-0002$-4858-3677$ 
del turismo, por lo que promueven políticas de desregulación tal que beneficien su industria turística (Zhang y Round, 2008; Papatheodorou, 2010; Dobruszkes y Mondou, 2013; Fu y Oum, 2014; Lieshout et al., 2016).

Entonces, y según algunos estudios, el turismo internacional debe su imparable crecimiento en las últimas tres décadas gracias al estímulo de la industria de la aviación (Dimitriou et al., 2017). Ahora bien, esta industria ha tenido que experimentar una evolución significativa desde sus inicios. Un evento relevante marca un hito en la historia de la industria de la aviación civil, la Convención de Chicago (en diciembre de 1944), a partir de la cual da comienzo la regulación de la aviación civil internacional (OACI, 2006). Pero la regulación de la industria, a nivel internacional, a través del desarrollo de políticas regulatorias muy estrictas, y hasta restrictivas, afectó al mercado de la competencia influyendo, negativamente, en el precio de los pasajes, en la demanda y finalmente en el flujo / movimiento de turistas (Forsyth, 2006). Pero la industria presenta un gran cambio en el año 1978, cuando en Estados Unidos se liberaliza el sector aerocomercial, evento que continuó en Europa en la década de 1980, y luego en el resto del mundo a diferentes velocidades (Levine, 2006; Winston y Peltzman, 2000; Morrison y Winston, 1995; Belobaba et al., 2009; Burghouwt y de Wit, 2015; Dobruszkes, 2009). La liberalización de la industria concatenó una serie de eventos relevantes, a saber, intercambio de derechos de tráfico (a través de la firma de convenios bilaterales), privatización de las líneas aéreas de bandera, entrada a los mercados de nuevos operadores aéreos privados, en especial los operadores charter y las líneas aéreas de bajo costo, acuerdos de cielos abiertos, generación de las grandes alianzas entre los operadores aéreos, y finalmente la comercialización y privatización de aeropuertos como así también la flexibilización de sus propias políticas regulatorias (Díaz Olariaga, 2017a; Doganis, 2006; Wittmer et al., 2011; Fu et al., 2015). Todo ello, que sigue aún su curso, eliminó barreras proteccionistas, propició la competencia, las tarifas se redujeron y estimuló la demanda, triplicando el tráfico aéreo mundial en las últimas tres décadas (ACI, 2019), situación de la cual se benefició de forma directa la industria del turismo a escala mundial.

En Colombia se liberaliza la industria del transporte aéreo en 1991 y experimenta todos los eventos que se produjeron a nivel mundial (antes citados), dicha liberalización se desarrolla a través de una batería de políticas públicas diseñadas exclusivamente para el sector aéreo, y aún en proceso (Díaz Olariaga, 2016a).

Entonces, el presente artículo de revisión analiza la influencia del desarrollo de la industria del transporte aéreo colombiano, a través de sus políticas públicas, en la dinámica del flujo turístico vía aérea, tanto a nivel interior o doméstico como hacia / desde el exterior. La metodología del trabajo se desarrolla de la siguiente manera (considerando que el tipo o carácter del artículo es de revisión): en primer lugar, se realiza una revisión de la bibliografía con el objetivo de conocer la producción científica que interrelaciona el transporte aéreo y el turismo y el enfoque de dichos estudios en la temática y presentar muy brevemente los resultados más relevantes obtenidos en dichas investigaciones. Paso seguido se desarrolla en extenso el caso de estudio, y en diferentes dimensiones, a saber: las políticas públicas del transporte aéreo, la influencia del transporte aéreo en la conectividad del país, evolución del flujo turístico vía aérea en Colombia (núcleo central del presente trabajo), y por último la interrelación existente en Colombia entre el transporte aéreo, el turismo y el posconflicto bélico. En siguiente lugar, se presentan las líneas de acción que deben seguir las futuras políticas públicas aéreas en función de las estrategias definidas y establecidas por las políticas públicas turísticas. Finalmente, la investigación se cierra con las oportunas conclusiones finales. Y para concluir, mencionar que el principal aporte de la presente investigación es contribuir a llenar el vacío en la literatura científica en la temática a su carácter geográfico, es decir, en general a nivel Latinoamérica, y en particular a nivel Colombia.

\section{Revisión de la Bibliografía}

La producción científica/bibliográfica de la interrelación transporte aéreo y turismo ha sido prolífica en las últimas dos décadas y en donde se han tratado muchas de las vertientes de dicha interrelación. Spasojevic et al. (2017) realizaron una detallada revisión de la bibliografía de la interrelación entre transporte aéreo y turismo. Anteriormente, Duval (2013) realizó una investigación similar (posiblemente la primera de su tipo) donde desarrolla una revisión de los problemas actuales del transporte aéreo en relación con el turismo. A continuación se presentan algunas investigaciones relevantes en la línea 
del presente trabajo, es decir, la influencia de la política pública del transporte aéreo (o aviación) en el desarrollo del turismo (en diferentes países y/o regiones del mundo).

Warnock-Smith y Morrell (2008) llevaron a cabo un estudio sobre la influencia de la liberalización del transporte aéreo en el tráfico aéreo de pasajeros en economías fuertemente dependiente del turismo, y como caso de estudio los autores escogieron algunos países del Caribe. El principal resultado del estudio verifica que los cambios en la política aérea regional facilitan el crecimiento del tráfico aéreo turístico en la región. En otro estudio posterior, Warnock-Smith y O'Connell (2011) probaron la hipótesis de que existen importantes relaciones indirectas entre los cambios en la política aérea nacional y los niveles de turismo entrante (receptivo). Los hallazgos del estudio demuestran que el tráfico aéreo entrante y, en consecuencia, el gasto turístico entrante se puede estimular a través de cambios en la política pública de transporte aéreo.

Costa et al. (2017) indagan el impacto de la liberalización del transporte aéreo en Brasil en la concentración de vuelos en muy pocos nodos (aeropuertos) de la red y la manera en que dicha circunstancia ha influido (negativamente) en la industria turística del país. Los autores creen necesario el desarrollo de una herramienta precisa para identificar y monitorear la concentración de vuelos en la red de transporte aéreo brasileño y su importancia para el turismo.

Dobruszkes y Mondou (2013) analizan en qué medida la liberalización del mercado de las aerolíneas entre la Unión Europea y Marruecos ha provocado cambios significativos tanto en los servicios aéreos como en los viajes de placer, contribuyendo así al plan maestro de turismo de Marruecos para atraer a 10 millones de turistas. De los resultados de la investigación los autores afirman que sin la liberalización y el crecimiento de los servicios aéreos, la demanda no podría haber crecido tanto como lo hizo en el periodo de estudio. Finalmente, estos autores concluyen que los países interesados en expandir sus actividades turísticas pueden considerar cambios en sus sistemas regulatorios (del mercado aerocomercial) para mejorar la accesibilidad internacional al país.

En un estudio realizado sobre algunos países de la zona Asia-Pacífico Zhang y Findlay (2014) encuentran evidencia de que el tráfico de pasajeros entre pares de ciudades se ha visto obstaculizado por ciertas políticas restrictivas de transporte aéreo, generando también un impacto negativo importante en los flujos turísticos bilaterales. Los autores concluyen que una mayor liberalización del sector del transporte aéreo podría ayudar a construir una industria turística más fuerte en los países de la región.

Galli et al. (2016) analizan el contexto de los flujos turísticos internacionales vía aérea hacia Brasil, aplicando los principios del modelo gravitacional. De entre sus conclusiones los autores afirman que para impulsar el turismo internacional hacia Brasil por vía aérea se debe trabajar en temas relacionados con la competitividad general del país como destino turístico internacional.

Yarde y Jonsson (2016) realizan un análisis sobre la liberalización del transporte aéreo en CARICOM (Comunidad de Estados del Caribe) y sus implicaciones en el turismo regional a Barbados (estado miembro de CARICOM). Los resultados del estudio muestran que mejoras en el entorno regulatorio del transporte aéreo en CARICOM ayudarían a mejorar el turismo intrarregional.

Alsumairi y Tsui (2017) investigaron el impacto de las líneas aéreas de bajo costo (LCC - Low-Cost Carrier) en la demanda turística en Arabia Saudita. También proporcionaron una comprensión de la relación entre el desarrollo del transporte aéreo y el desarrollo del turismo en la región del Golfo Pérsico. Los hallazgos empíricos de dicho estudio han demostrado que un aumento en la capacidad de asientos de las aerolíneas tanto de las FSC (Full-Service Carrier) como de las LCC se asocia con un aumento significativo en el número de llegadas mensuales de turistas internacionales a Arabia Saudita; los autores sugieren también que el crecimiento de la capacidad de transporte aéreo estimuló las llegadas de turistas internacionales.

Wu (2016) realiza una investigación para explorar la medida en que la desregulación del transporte aéreo en Japón ha afectado el negocio de vuelos charter en los mercados de Japón-Corea, Japón-Taiwán y Japón-China, y a su vez cómo esta circunstancia ha afectado el turismo de entrada a Japón. Los resultados revelan que la desregulación de la aviación de Japón ha traído cambios profundos (y positivos) al negocio de vuelos charter, por lo que el autor afirma que se espera que la experiencia de Japón brinde orientación en la formulación de políticas de transporte aéreo y de turismo en los países de la región Asia-Pacífico. En un estudio más reciente, y en la misma línea, Wu et al. (2018) revisa los cambios en las políticas de transporte aéreo, en un periodo reciente de siete años, y evalúa los efectos de esos cambios en los flujos turísticos, centrándose en las rutas servidas por los vuelos charter, todo ello aplicado al mercado de China y Taiwan. 
Finalmente, Dimitriou et al. (2017) cuantifican el impacto socio-económico del transporte aéreo en regiones/países que dependen fuertemente del turismo, y usan como caso de aplicación (o de estudio) a Grecia. Los resultados de su investigación indican que el transporte aéreo es un factor clave del desarrollo del sector turístico; los autores afirman que mientras la industria del transporte aéreo tiene una contribución directa e indirecta esencial al ingreso nacional, los efectos catalíticos son más del doble para una economía turística como la de Grecia. Los resultados también sugieren que la inversión en infraestructura de transporte aéreo estimula el crecimiento económico y fortalece los valores sociales y genera empleo.

Y en lo que concierne al país caso de estudio del presente estudio (Colombia), Díaz Olariaga y López (2016) realizaron una caracterización simultánea del desarrollo de las industrias del transporte aéreo y del turismo en Colombia y evaluaron sus impactos en la economía colombiana.

\section{Política pública del transporte aéreo en colombia}

\section{La privatización de aeropuertos en Colombia}

Sobre la gestión de la infraestructura aeroportuaria Colombia ha seguido la tendencia general en América Latina de concesionar al sector privado la administración de dichas infraestructuras (Díaz Olariaga, 2017b; Espirito Santo, 2013; Serebrisky, 2012; Mendiola et al., 2011; Carvallo, 2008; Lipovich, 2008; Rico Galeana, 2008; Bosch y García Montalvo, 2003; Espirito Santo et al., 2001). Este modelo busca liberar al Estado del alto gasto requerido por la infraestructura aeronáutica. Este proceso está regulado por una ley nacional (Ley 80 de 1993, artículo 30). Por otra parte, el Estado a través de otra norma (DNP, 1994) consagró el proceso de concesiones de aeropuertos a través de un plan de ordenamiento de la infraestructura aeroportuaria. El documento además de plantear una renovación tecnológica, autorizó el proceso de concesión de los aeropuertos a empresas privadas, y consideró la contraprestación económica para el Estado como único elemento para entregar la concesión. A esta contraprestación se le definió como destino: a) alimentar el fondo de compensación aeronáutica para subsidiar a los aeropuertos no rentables, b) financiar nuevas inversiones en dichos aeropuertos y c) financiar los servicios de tráfico aéreo y seguridad (Díaz Olariaga y Ávila, 2015).

Entonces, desde 1996, y en varias fases temporales, denominadas generaciones, el sector público colombiano entregó en concesión al sector privado varios aeropuertos del país (un aeropuerto, o conjunto de varios, a diferentes grupos empresariales), un total de 19 a la fecha, los más grandes e importantes de la red aeroportuaria (Díaz Olariaga y Pulido, 2019) con el fin de obtener una mejor administración, modernización y expansión, operación, explotación comercial y mantenimiento de las terminales aéreas de mayor uso. Bajo el objetivo planteado de las concesiones aeroportuarias del país, la empresa, sociedad, consorcio o ente concesionario de los aeropuertos se desempeña únicamente como administrador del mismo.

En otro orden, la política de concesiones de aeropuertos vino acompañada de una política de inversión pública que no ha cesado desde hace dos décadas. Y por otro lado, la inversión privada en aeropuertos ha evolucionado de acuerdo a la dinámica propia de las concesiones, pasando de inexistente en 1996, año cero de inicio de las primeras concesiones, a un $20 \%$ como porcentaje del PIB del transporte aéreo en 2010 (Díaz Olariaga, 2016b). Mencionar que estas políticas orientadas a la modernización de las infraestructuras del trasporte aéreo están, en algunos aspectos, alineadas con los diferentes planes sectorial (cuatrienales) del sector turismo en Colombia (Díaz Olariaga, 2015), de entre cuyas estrategias (relacionadas a la presente investigación) se pueden citar: a) impulsar el desarrollo y consolidación de destinos y productos turísticos competitivos y sostenibles a nivel regional y territorial, y b) impulsar la conectividad para el turismo del país a nivel regional, nacional e internacional (DNP, 2014).

\subsection{El mercado de los operadores aéreos}

Una de las barreras más importantes de acceso a los mercados es la reglamentación y los controles a las rutas, capacidad y tarifas. En lo que refiere al mercado local o doméstico, Colombia ha pasado en los últimos 25 años de un esquema proteccionista a un esquema de libertad vigilada (Díaz Olariaga, 2016b). Ahora bien, aunque la política de acceso al mercado nacional ha sido objeto de una liberalización gradual en años recientes todavía se establece un número máximo de operadores para las rutas de pasajeros, y hasta el año 2012 se mantenía un control sobre las tarifas de los tiquetes aéreos que se venía flexibilizando paulatinamente, pero desde ese año las tarifas aéreas están totalmente desreguladas (Díaz 
Olariaga y Zea, 2018). El efecto inmediato de la liberalización tarifaria fue la disminución sustancial de las tarifas fijadas por las empresas tanto para los destinos nacionales como internacionales. En otro orden, este efecto fue coherente con los fines de las políticas de competencia y además con la promoción de los servicios relacionados con el turismo. Por ello, la decisión de eliminar los precios mínimos, cuyo efecto fue el aumento de la competencia en el mercado, estuvo acorde con la política gubernamental de promover el turismo, y fue coherente también con el principio de competencia abierta establecido en la Ley General de Turismo (Ley 300 de 1996) (Miranda y Gutiérrez, 2008).

Con respecto al mercado internacional, en Latinoamérica las iniciativas de integración y flexibilización del tráfico aéreo han avanzado impulsadas fundamentalmente por las autoridades aeronáuticas y de comercio. Colombia no es ajena a este panorama de desarrollo mundial, habiendo pasado de un modelo proteccionista de restricciones de acceso y control de tarifas a un enfoque intermedio de apertura gradual a partir de 1991-1992. Es en los últimos 25 años que se cuenta con una extensa relación de acuerdos bilaterales, cuyo objetivo ha sido la armonización de las políticas en el otorgamiento de derechos de tráfico, la regulación de las condiciones de acceso a los mercados y la fluidez del transporte aéreo (Díaz Olariaga, 2016a; ORE, 2011; IADB, 2007; CAF, 2006). A partir de 2009 se consolida una política de desregularización total a través de la promoción de firmas de acuerdos de mayores libertades hasta los llamados cielos abiertos con los países con los que se tienen vínculos aéreos para garantizar un mercado plenamente libre, con el objetivo de avanzar hacia el libre acceso al mercado y de tarifas (ORE, 2009). Por ello, en el periodo 2010-2018 se firmaron (nuevos) convenios con 29 países (DNP, 2018).

En otro orden, en Colombia la entrada al mercado de operadores aéreos privados con un modelo de negocio tradicional, o FSC (Full-Service Carrier), se produjo muy pronto luego de la liberalización del sector (mediados de la década de 1990). Pero la entrada al mercado de las líneas aéreas con un modelo de negocio de "bajo costo" fue muchos años posterior a la liberalización, recién en la última década (Díaz Olariaga, 2016a).

\section{Situación del transporte aéreo en la conectividad del país}

Se puede afirmar que el transporte aéreo en Colombia prácticamente no tiene competencia (a nivel doméstico) con otros medios de transporte, sobre todo para distancias medias y largas (Díaz Olariaga et al., 2018). Esta situación viene reforzada debido a tres factores determinantes. En primer lugar, la compleja geografía del país (atravesado de suroeste a noreste por tres cadenas montañosas de la Cordillera de Los Andes). En segundo lugar, existe una gran deficiencia (en cobertura y capacidad) de los sistemas de comunicación terrestre-vial (no existencia de autopistas de media o alta capacidad); Colombia tiene una deficiencia de 65 mil kilómetros de carreteras, en comparación con indicadores de la región (Latinoamérica) (Yepes et al., 2013). Y en tercer lugar, situación similar, negativa, se verifica con el sistema de transporte ferroviario, en donde el mismo solo se utiliza para el transporte carga, no para pasajeros (Diaz Olariaga y Carvajal, 2016), y así y todo, el sistema de transporte férreo necesita más 4 mil kilómetros de vías férreas (para mejorar el transporte de carga) (Yepes et al., 2013).

En otro orden, Colombia concentra todo su desarrollo poblacional, económico y productivo en la región central, oeste y norte del país (Andina, Pacífica y Caribe respectivamente). Por ello la red aeroportuaria, y sobre todo sus principales aeropuertos, se concentran también en dichas regiones (ver Figura 1), en definitiva la geografía del sistema aeroportuario y su desarrollo coincide y es coherente con la geografía socio-económica del país, garantizando así, al menos al nivel de estructura de red, una amplia cobertura territorial (Díaz Olariaga y Carvajal, 2016).

Finalmente, en lo que se refiere a regiones remotas, aisladas y periféricas, en Colombia existe una región insular, el Archipiélago de San Andrés, Providencia y Santa Catalina, al cual solo se puede llegar, desde el territorio continental colombiano, vía aérea; por otro lado el país cuenta con regiones / ciudades remotas de nulo acceso vía terrestre, como por ejemplo las que se encuentran en la Amazonia, que en este caso bien podrían designarse como regiones aisladas (ya que solo se puede llegar / acceder vía aérea); y finalmente existen varias regiones periféricas, entendiendo por tal no solo su gran distancia a las principales ciudades del país, sino también su difícil acceso vía terrestre, debido no sólo a la propia y accidentada orografía (o relieve) del país sino también a la inexistencia de una red principal de carreteras que cubra todo el territorio nacional (Díaz Olariaga y Carvajal, 2016, 2017). 
Figura 1: Ubicación geográfica de los aeropuertos de la red abiertos al tráfico comercial (que gestionan vuelos programados). Descripción: con un círculo azul se identifican los aeropuertos con gobernanza privada (concesionados); con triángulo rojo se identifican los aeropuertos con gobernanza pública; BOG es el código IATA del principal aeropuerto del país en su capital (Bogotá).

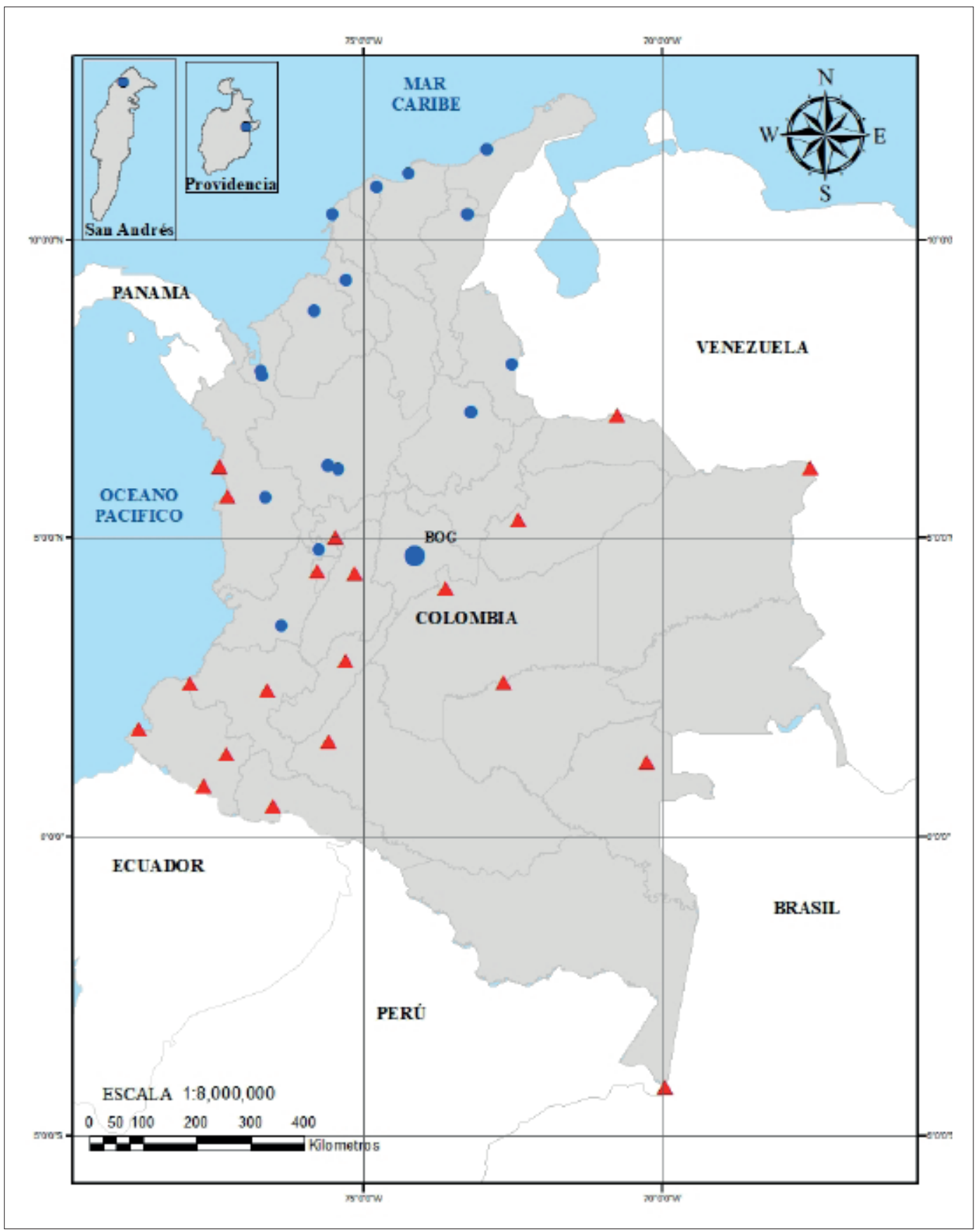

Fuente: Aerocivil, 2020. 


\section{Evolución del flujo turístico vía aérea en colombia}

\subsection{Desarrollo general del tráfico aéreo}

En primer lugar, se considera oportuno mostrar el impacto que tuvieron las políticas públicas del transporte aéreo, implementadas luego de la liberalización de la industria (año 1991) en el desarrollo del tráfico aéreo. Entonces, la Figura 2 muestra la evolución de la demanda de pasajeros aéreos, nacionales e internacionales, y de la misma se puede destacar: a) el crecimiento relevante de la demanda da inicio en 2006, cuando se privatiza el principal aeropuertos del país Bogotá-El Dorado (en adelante BOG, en el cual se invirtió USD 650 millones para su ampliación y modernización) y potenciado por las siguientes generaciones de concesiones (2008, 2010 y 2015) (Díaz Olariaga, 2017b); b) el motor del crecimiento del tráfico aéreo fueron los vuelos domésticos (o nacionales); c) durante casi una década (2006-2014) el crecimiento (medio anual) del tráfico aéreo colombiano fue superior a la media regional y mundial (Díaz Olariaga y Ávila, 2015); y d) la caída de la demanda en el año 2017 se debe a la huelga de pilotos de la principal aerolínea del país (Avianca) y que duró 51 días (donde se cancelaron 10.000 vuelos).

Figura 2: Evolución del tráfico aéreo colombiano.

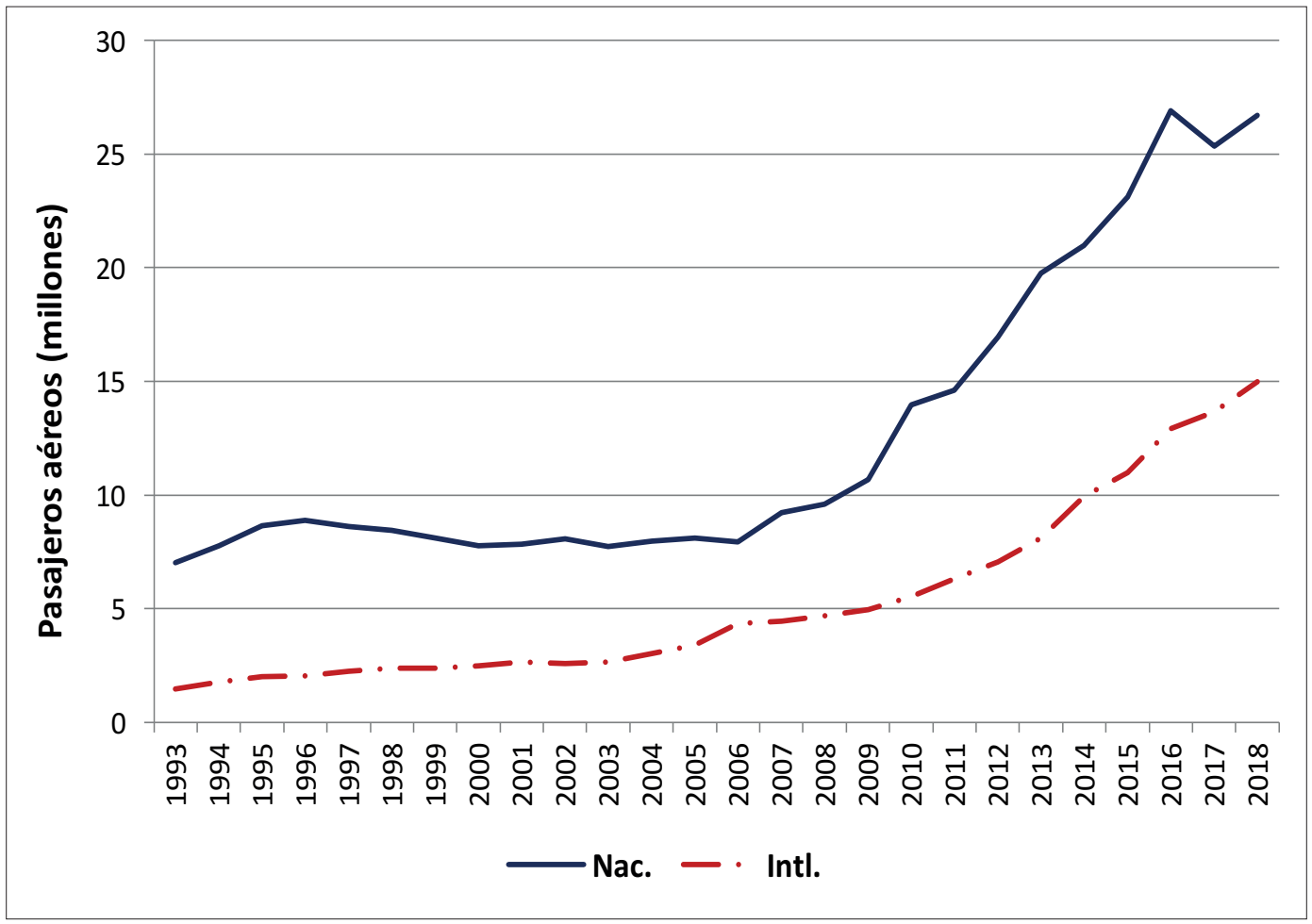

Fuente: Aerocivil, 2020.

Ahora bien, aunque el indicador mostrado en la Figura 1 dice mucho sobre el crecimiento de pasajeros transportados, en transporte aéreo se utiliza, más frecuentemente, el indicador denominado "pasajero-kilometro transportado", o más usado en su acrónimo en inglés RPK (Revenue Passenger Kilometers), que suministra una medida más exacta del tráfico real, ya que considera la distancia que el pasajero recorre en su viaje. Este indicador ayuda a identificar y dimensionar la cobertura geográfica de un aeropuerto (en distancia hacia sus diferentes destinos). Entonces, en el caso de Colombia, el RPK del sistema aeroportuario ha experimentado un relevante y mantenido crecimiento en la última década, producto de la entrada al mercado de nuevos operadores aéreos internacionales (con rutas y frecuencias 
a destinos cada vez más lejanos), resultado de las políticas públicas implementadas (eliminación de barreras proteccionistas, firma de convenios bilaterales con varios países, avances importantes en la política de "cielos abiertos", desregulación tarifaria, etc.) (Díaz Olariaga, 2016b). Entonces, la Figura 3 muestra la evolución del RPK del conjunto de aeropuertos de Colombia; el crecimiento del RPK nacional se debe exclusivamente al aumento de destinos y de la oferta de sillas y frecuencias por parte de los operadores aéreos (mencionar que la red de aeropuertos se ha mantenido inalterable en las últimas cuatro décadas). Mientras que el crecimiento del RPK internacional es el resultado, además del aumento de la oferta de sillas y frecuencias, del aumento de destinos internacionales directos que conectan a Colombia con el exterior, el cual se ha casi duplicado en los últimos 25 años (Aerocivil, 2020). Este continuo aumento de la oferta de servicio de transporte aéreo, como respuesta a una creciente demanda, fue posible también gracias al aumento de la capacidad en infraestructura (y modernización tecnológica) de la red colombiana de aeropuertos, producto a su vez del desarrollo de políticas públicas de inversión (público y privada) en dicha red implementas a lo largo de las últimas dos décadas (Díaz Olariaga, 2016b).

Figura 3: Pasajero-kilómetro transportado (RPK) Colombia.

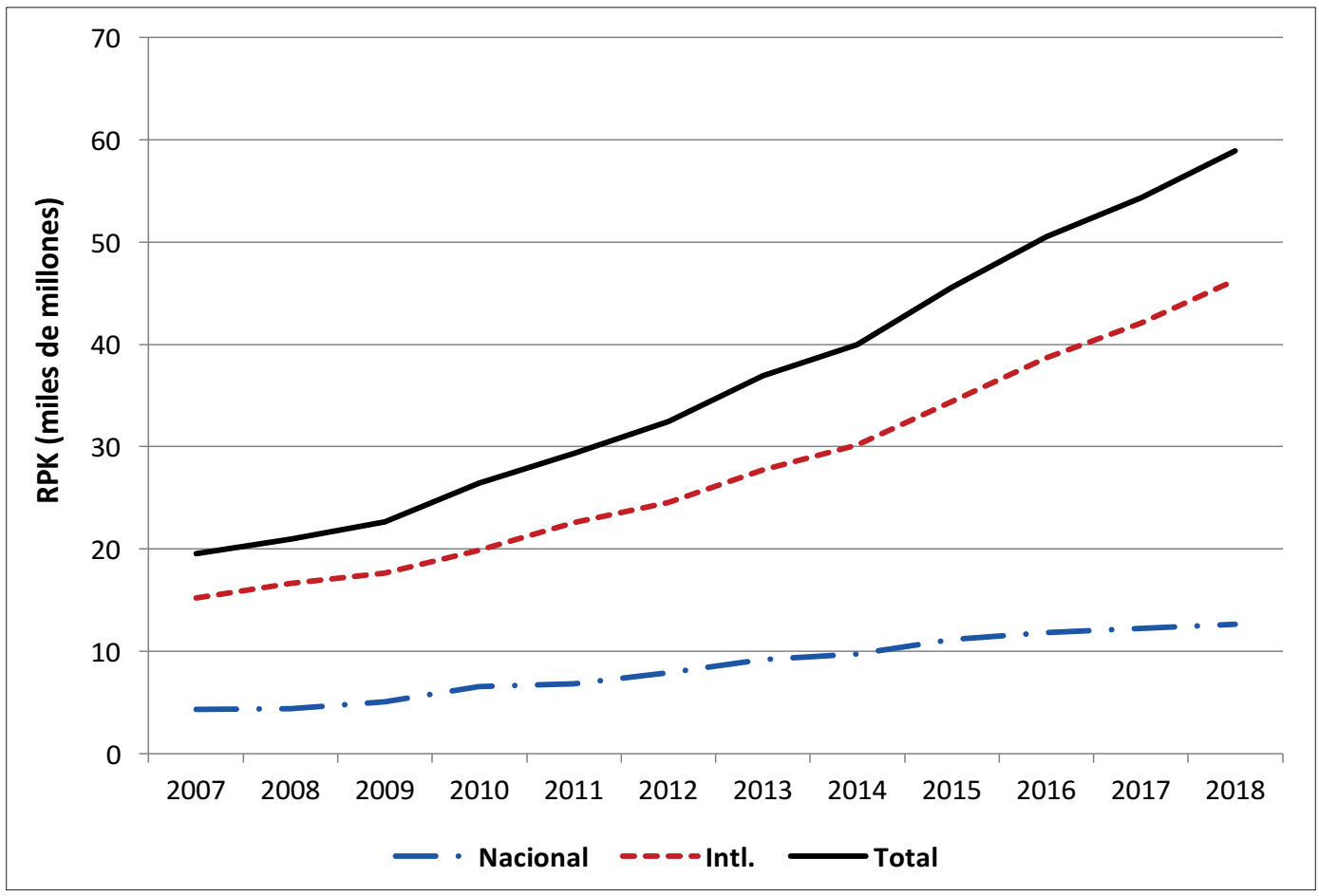

Fuente: Aerocivil, 2020.

\subsection{Evolución de la entrada y salida de turistas vía aérea}

La entrada de turistas extranjeros (no-residentes) (turismo receptivo) y la salida de turistas colombianos residentes al extranjero (turismo emisor) vía aérea creció un $562 \%$ y $330 \%$ respectivamente en el periodo 2001-2018 (ver Figura 4).

En las Figuras 5 y 6 se muestra, para 2018, los principales países-origen de los turistas extranjeros entrantes y los países-destino de los turistas colombianos salientes, respectivamente. Sobre este indicador mencionar que, con respecto a hace dos décadas, aunque los Estados Unidos sigue siendo el principal origen y destino de turistas entrantes (extranjeros) y salientes (colombianos), los índices han disminuido en beneficio de otros orígenes/destinos, principalmente del resto de Latinoamérica y de Europa (MinCIT, 2020; DANE, 2006). 
Figura 4: Entrada y salida de turistas vía aérea (2001-2017).

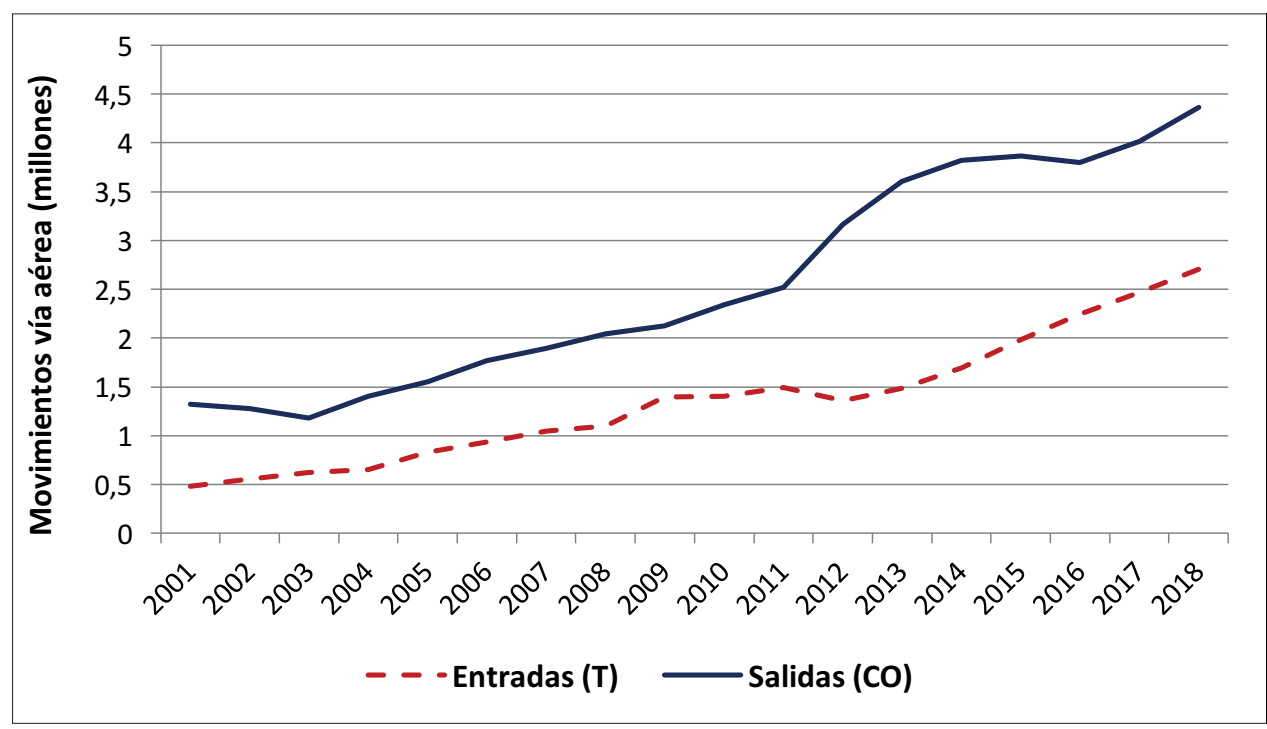

Fuente: MinCIT (2020).

Leyenda. Entradas (T): entrada de turistas extranjeros no-residentes (no incluye colombianos residentes en el extranjero, ni visitantes extranjeros por trabajo/negocios ni extranjeros residentes en Colombia. Salidas (CO): salidas de turistas colombianos (residentes en Colombia).

Figura 5: Principales orígenes del turismo receptivo vía aérea (2018), porcentaje sobre el total de ingresos.

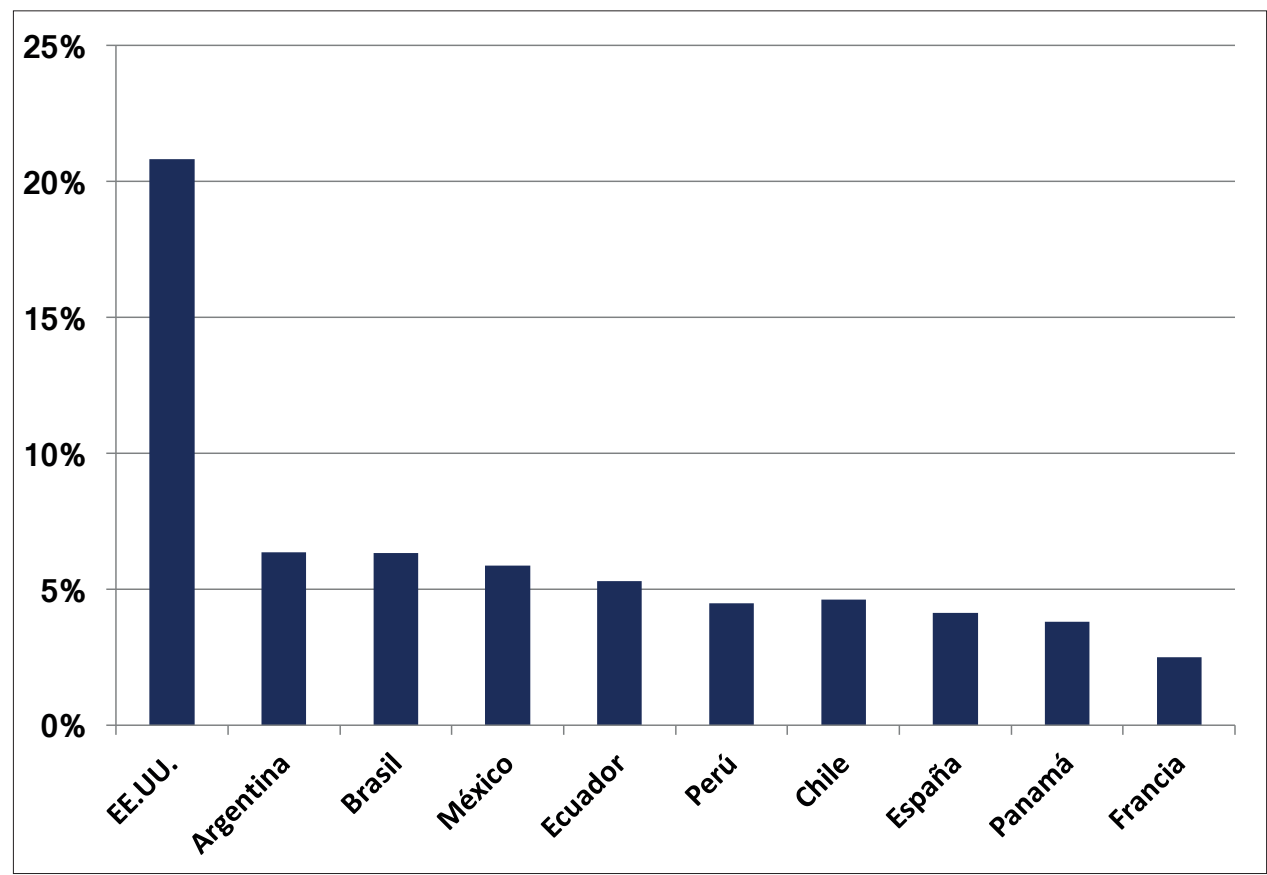

Fuente: MinCIT (2020). 
Figura 6: Países destinos de turistas colombianos vía aérea (2018), porcentaje sobre el total de salidas.

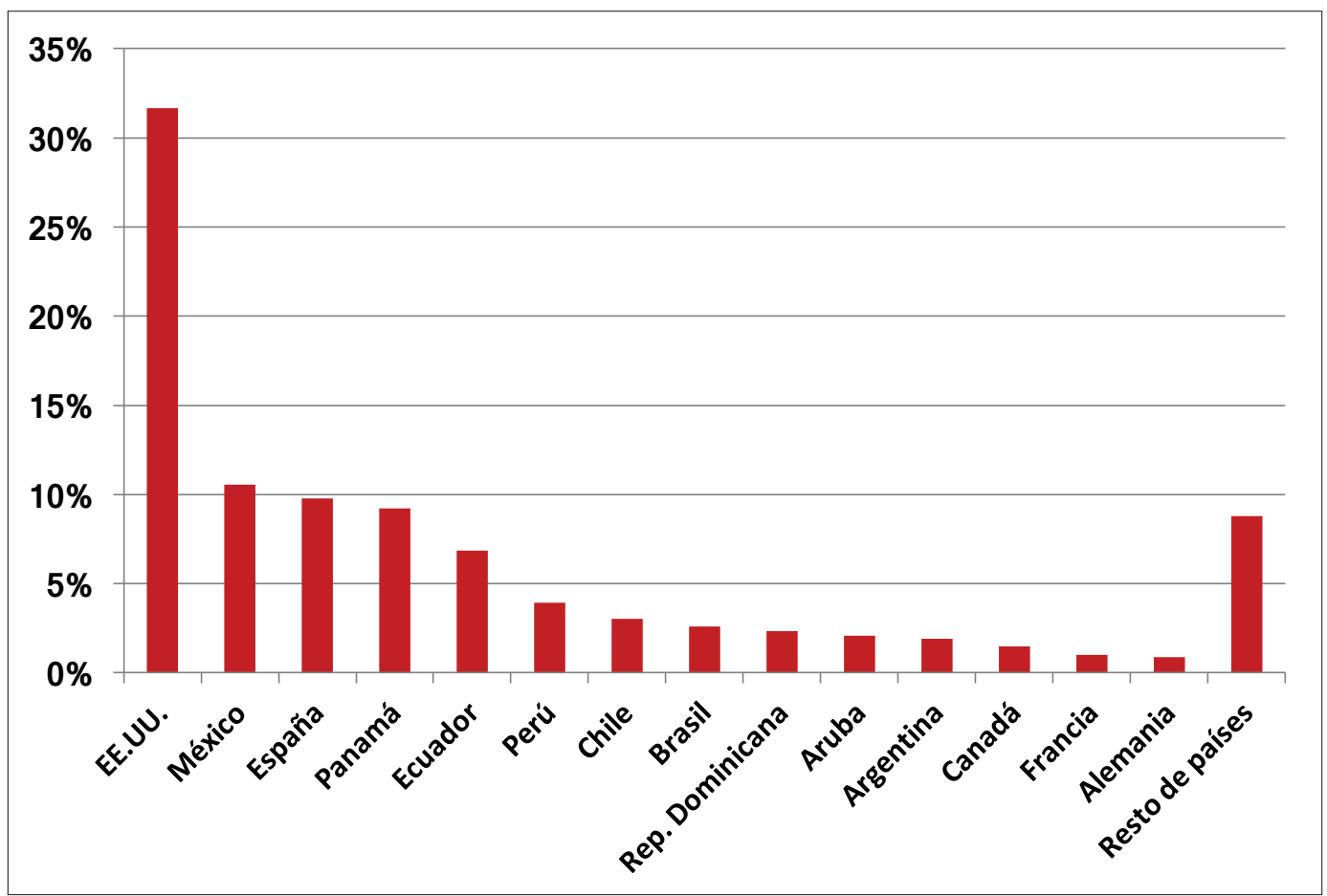

Fuente: MinCIT (2020).

\subsection{La influencia de la conectividad en el flujo turístico}

El transporte aéreo se desarrolla en un concepto de red donde los aeropuertos representan los nodos de la red, y en las últimas décadas se ha afianzado la estructura denominada hub-and-spoke, en donde unos pocos aeropuertos, denominados "distribuidores" $(h u b)$, concentran y distribuyen tráfico al resto de la red (Díaz Olariaga y Zea, 2018). En esa línea, en Colombia el aeropuerto distribuidor por excelencia está en la capital del país y es el de Bogotá-El Dorado (código IATA: BOG). Ahora bien, en la dinámica del crecimiento del tráfico, cuyos indicadores ya se han mencionado, en Colombia también se han desarrollado las denominadas "rutas principales nacionales" y "rutas principales internacionales", es decir, aquellas rutas que conectan destinos (ciudades) con altos niveles de tráfico a nivel doméstico e internacional respectivamente. En lo que se refiere a las rutas principales nacionales, las mismas tuvieron un crecimiento de entre el $200 \%$ y $1800 \%$ entre 1992 y 2018 (Aerocivil, 2020). De entre todas las rutas nacionales destacar que un importante crecimiento, del orden de 400-600\%, en las rutas de las principales ciudades del centro del país hacia las ciudades de la costa del Caribe, zona turística por excelencia en Colombia (Díaz Olariaga y López, 2016).

En otro orden, y a diferencia de la red doméstica de transporte aéreo, cuyo número de destinos nacionales se ha mantenido inalterable en las últimas décadas debido a que no se han construido nuevos aeropuertos, no pasa lo mismo con la red de destinos internacionales. La ampliación y modernización de los principales aeropuertos del país (todos ellos ya privatizados), la mayoría de carácter internacional, permitió a los operadores aéreos aumentar su oferta internacional de destinos, sillas y frecuencias. Por ello, en las últimas dos décadas y media, el número de destinos internacionales directos que conectan a Colombia con el mundo prácticamente se han duplicado (Aerocivil, 2020), y donde se destaca la incorporación de grandes destinos (largas distancias) en los extremos (norte y sur) del continente americano y Europa. En la Figura 7 se presenta la evolución temporal de los destinos internacionales directos que conectan Colombia con el mundo (rutas principales internacionales). 
Figuras 7: Red de destinos internacionales directos desde Colombia. Comparativa entre años 1992 y 2016.

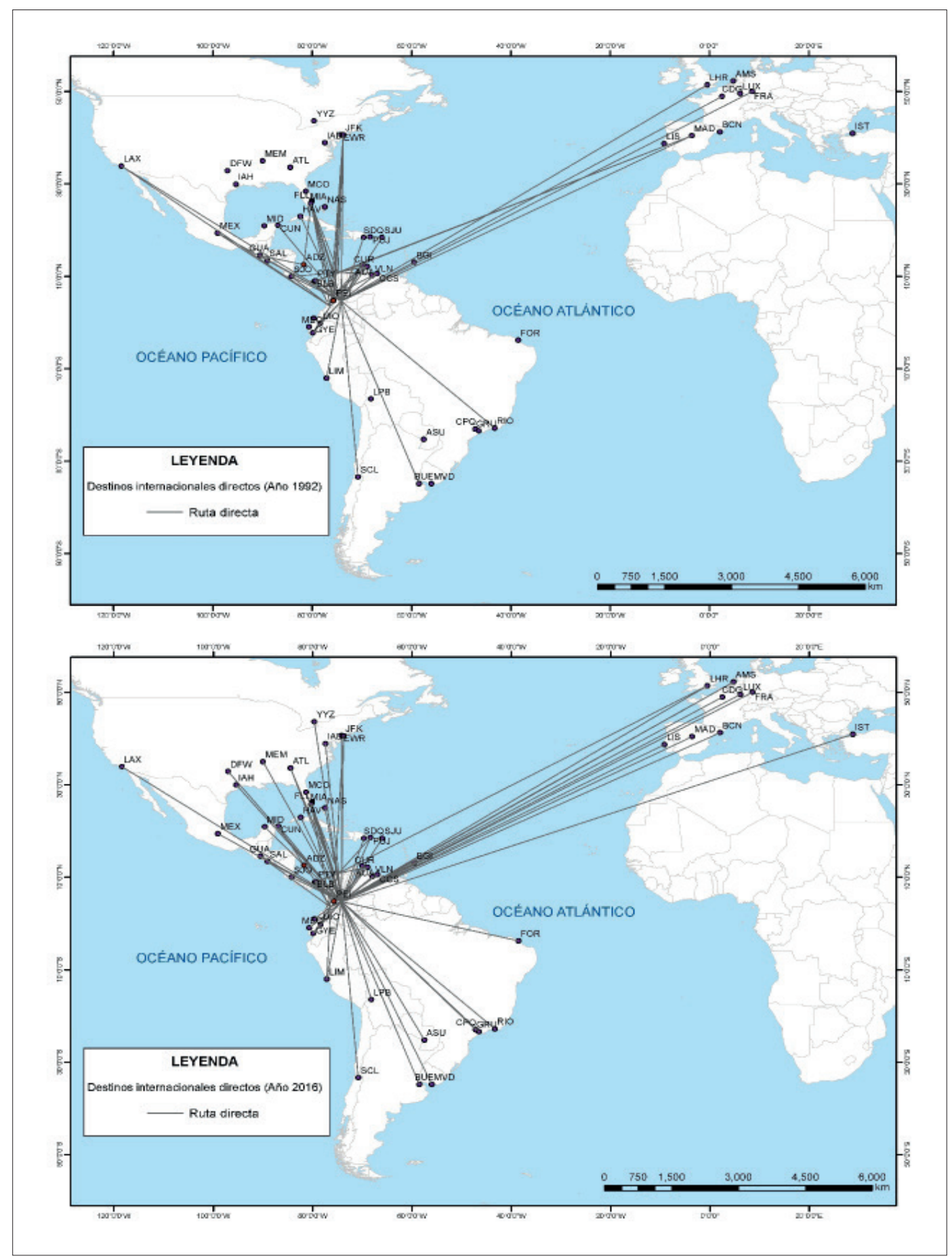

Fuente: Aerocivil, 2020. 


\section{Transporte aéreo, turismo y posconflicto bélico}

La firma del Acuerdo de Paz entre el gobierno colombiano y las Fuerzas Armadas Revolucionarias de Colombia-Ejército del Pueblo (FARC-EP), en noviembre de 2016, ha tenido una influencia en el crecimiento del turismo (tanto emisor como receptivo), materializada en el incremento de más de un $27 \%$ del número de llegadas de turistas extranjeros (vía aérea) desde que dio comienzo el periodo de posconflicto (MinCIT, 2020; Menchero, 2018).

En el nuevo escenario de posconflicto, el gobierno colombiano considera al turismo como un sector económico que posibilita el crecimiento y desarrollo de muchas zonas / regiones de Colombia. Por ello, el Plan Nacional de Desarrollo 2014-2018, en línea con el Plan Sectorial de Turismo "Turismo para la Construcción de la Paz (2014-2018)" estructuró, para el desarrollo común, varios ejes estratégicos y/o temáticos, de entre los cuales se encuentra la conectividad aérea y sus infraestructuras asociadas, más específicamente, se propuso la mejorar la calidad de las infraestructuras aeroportuarias en todos aquellos destinos con alto potencial turístico (DNP, 2014).

Actualmente, el Plan Nacional de Desarrollo 2018-2022 (DNP, 2019) establece que el Ministerio de Comercio, Industria y Turismo implementará los lineamientos e iniciativas del Plan Sectorial de Turismo 2018-2022 (MinCIT, 2018). Una de las líneas estratégicas de dicho plan establece acciones para el desarrollo de infraestructura de conectividad (todos los modos) para el turismo.

Y finalmente, y en otro orden, de entre los lineamientos de política del sector aéreo, estructurados en el Plan Estratégico Institucional 2019-2022 (Aerocivil, 2019), y éste a su vez emanado del Plan Estratégico Aeronáutico 2018-2030, en su línea de acción "Conectividad y Competitividad", se propone: a) desarrollar una política clara conjunta con el Departamento Nacional de Planeación y el Ministerio de Hacienda para los aeropuertos que prestan Servicios Aéreos Esenciales (para prestar el servicio de transporte en los territorios aislados); y b) desarrollar e integrar la política de turismo y paz del posconflicto.

\section{Estrategias de política aérea a desarrollar para el turismo}

En Colombia el Plan Sectorial de Turismo 2018-2022 (MinCIT, 2018) incluye seis líneas estratégicas: (1) generación de condiciones institucionales para el impulso al sector turismo; (2) gestión integral de destinos y fortalecimiento de la oferta turística; (3) atracción de inversión, infraestructura y conectividad para el turismo; (4) innovación y desarrollo empresarial en el sector turismo; (5) fortalecimiento del capital humano para la competitividad del turismo; y (6) promoción de un turismo transformador, incluyente y con equidad. Entonces, el Plan Sectorial solicita y recomienda al gobierno nacional el diseño y ejecución de políticas públicas aéreas orientadas y alineadas con estas líneas estratégicas y que deben abordar las siguientes aspectos relevantes (MinCIT, 2018).

Precio de pasajes aéreos: Colombia presenta impuestos y tasas aeroportuarias de entre los más altos del mundo. De hecho, se han identificado cerca de 14 tributos que gravan la industria de transporte aéreo. En Colombia, para los operadores aéreos los costos aeroportuarios representan alrededor del $8,3 \%$, siendo un valor muy superior frente a otros países de Latinoamérica, lo cual evidencia que existe una posibilidad de mejora para las empresas aéreas frente a la reducción de estos factores.

Precio del combustible de aviación: en Colombia el precio del combustible de aviación es uno de los más alto a nivel internacional, resultado de los mayores impuestos que sufre este insumo en el país. Esta situación genera un considerable aumento de los costos operativos de los operadores aéreos, los cuales trasladan directamente a los consumidores (vía el precio de los pasajes aéreos). Esto conduce a una merma en la competitividad en la conectividad aérea con respecto a otros mercados turísticos. Por tal razón, ajustar este marco tributario y de costos es fundamental para aprovechar las oportunidades de Colombia en el crecimiento esperado del mercado aéreo y para atraer más turismo extranjero.

Inversión en infraestructura aeroportuaria: el actual Plan Sectorial de Turismo establece que para no frenar el actual desarrollo turístico vía aérea, e incluso para dinamizarlo aún más, se requiere que la infraestructura aeroportuaria no tenga limitaciones para absorber la nueva demanda. Y este requerimiento se debe extender más allá de los principales aeropuertos del país, debe intentar cubrir la mayor parte de la red aeroportuaria nacional. En esta línea, mencionar que el gobierno nacional ya viene trabajando desde hace 25 años con políticas relacionadas. Por ejemplo, entre los años 1993 y 2013 la inversión pública en infraestructura aeroportuaria fue de aproximadamente USD 1.000 millones; mientras que la inversión privada, producida en las diferentes generaciones de concesiones aeroportuarias (total 18 aeropuertos), periodo 1996-2015, fue de USD 1.612 millones (Fedesarrollo, 2016); y finalmente, 
el Plan Maestro de Transporte Intermodal 2015-2035 prevé una inversión mixta (pública y privada) de USD 5.300 millones en todos los aeropuertos de la red en el periodo antes mencionado (ANI, 2019).

Acuerdos aéreos bilaterales: Colombia tiene acuerdos aéreos con 46 países, de los cuales se suscribieron 29 en la última década, sin embargo, se debe resaltar que solamente con Estados Unidos existe un acuerdo de cielos abiertos con quintas libertades. Los beneficios de este tipo de acuerdos se reflejan en el incremento de operadores aéreos, frecuencias y destinos, por ello el gobierno nacional debe seguir aumentando la consecución de este tipo de acuerdos con terceros países, en especial con aquellos de fuerte turismo emisor (hacia Colombia). La reducción de las barreras para mejorar las libertades aéreas promoverá la llegada de nuevos operadores aéreos lo que generará un incremento sustancial de viajeros extranjeros al país y la conectividad en beneficio de los usuarios nacionales. Por este motivo, es fundamental que la política aérea se enfoque en promover el tráfico a aeropuertos que puedan desarrollar operación internacional, y fortalecer los procedimientos en otros aeropuertos troncales con vocación a ser, a medio o largo plazo, un $h u b$ (distribuidor) internacional, además del Aeropuerto de Bogotá-El Dorado, principal hub del país.

Aeropuertos regionales: se deben adelantar acciones conjuntas con la autoridad pública aeronáutica y los actores del sector aeronáutico para contar con una infraestructura de aeropuertos regionales adecuadamente mantenida y permanentemente modernizada, en donde los aeropuertos de destinos con gran potencial turístico desarrollen su capacidad de atender la demanda del servicio.

Reducción de la burocracia aeronáutica: promover la facilitación de la operación de empresas de vuelos charter y aerolíneas del orden regional con destinos turísticos en el país, gestionando frente a la autoridad aeronáutica y las entidades competentes la simplificación de los trámites para la constitución de empresas y eliminando barreras de acceso al mercado sobre límite de sillas, rutas de operación y plazo. En este sentido, las políticas aéreas deben promover la promoción de operaciones de vuelos charter con mercados emisores internacionales prioritarios como eje dinamizador fundamental del turismo internacional.

Política aerocomercial: se deben impulsar esquemas de libertad tarifaria aérea para el desarrollo de nuevas rutas y destinos.

Políticas de conectividad: se deben desarrollar estrategias de conectividad para los destinos turísticos con las entidades nacionales y regionales competentes, fomentando la operación de empresas aéreas con vuelos no regulares (no programados) con aeronaves de mediana y pequeña capacidad. Se debe incrementar la conectividad entre las ciudades capitales y/o ciudades intermedias propiciando la apertura de nuevas rutas exentas de IVA a fin de fomentar el turismo interior.

\section{Discusión y conclusiones}

La presente investigación muestra como las políticas públicas en la industria de la aviación civil / transporte aéreo en Colombia han influido positivamente (en lo que a indicadores de tráfico se refiere) en el desarrollo y dinámica del flujo turístico vía aérea, tanto exterior (receptor / emisor) como interior. Sin lugar a dudas el impulsor de esta dinámica ha sido la liberalización de la industria iniciada a principios de la década de 1990. En esta línea, y desde hace dos décadas y media, se han desarrollado, de forma ininterrumpida, las políticas públicas en el sector, atacando las diversas vertientes de la industria: paulatina desregulación tarifaria, eliminación de barreras para la entrada de nuevos operadores aéreos al mercado, agresivos programas de inversión pública en infraestructuras del transporte aéreo, privatización de aeropuertos, firma de un gran número de convenios aéreos bilaterales (donde se potencia, en otros, el intercambio de derechos aerocomerciales), acuerdos de cielos abiertos, etc.

Todas estas políticas han conducido a que el transporte aéreo contribuya de manera importante a la economía colombiana, creando empleo y generando riqueza, para ser más precisos: 169.000 empleos (directos e indirectos) y una contribución bruta de valor agregado de USD 1.000 millones al PIB nacional (IATA, 2019). Y la importancia del transporte aéreo para la industria turística en Colombia lo reflejan los indicadores relacionados, por ejemplo, al año 2018 solo los turistas extranjeros que llegan a Colombia por vía aérea dan soporte a 432.000 empleos directos relacionados (en las empresas del sector turismo) y contribuyen en USD 5.300 millones a la economía nacional (IATA, 2019).

Los relevantes crecimientos de los indicadores turísticos que aquí se han presentado se han conseguido gracias a las políticas aéreas que han potenciado la "conectividad aérea", no solo a nivel doméstico sino también a nivel internacional, con el continuo aumento del número de rutas, la importancia de los (nuevos) destinos, la frecuencia de los servicios, y la oferta creciente de sillas. 
Las previsiones, al menos a corto plazo (Díaz Olariaga et al., 2017), anuncian un dinámico e importante crecimiento de la demanda de tráfico aéreo, y en todos los grandes aeropuertos del país. Esta situación invita a dar continuidad a las políticas públicas en el sector del transporte aéreo, y al parecer esa es la intención gubernamental. Ahora bien, en otro orden hay varios aspectos por mejorar, como por ejemplo la competitividad. En este sentido, un estudio reciente revela que Colombia es uno de los países menos competitivos de Latinoamérica en materia aerocomercial, debido a su política de tasas e impuestos a los billetes aéreos que frena la demanda y con ello el crecimiento (CEPAL, 2017). Este mismo estudio advierte, y ya para toda Latinoamérica, que la implementación de políticas públicas no favorables en el sector del transporte aéreo podrían mermar el crecimiento previsto de tráfico, para el año 2036, en aproximadamente 400 millones de pasajeros (CEPAL, 2017).

Finalmente, aunque las actuales políticas públicas tanto en el sector transporte aéreo como turístico en el país están, aparentemente, alineadas (y sólo en algunos aspectos), no se ve claro que haya una estrategia de mutuo reforzamiento o aprovechamiento de sinergias, sobre todo en aquellos aspectos claves que las vincula fuertemente. Posiblemente sea una consecuencia de que originalmente ambas políticas nacieron muy a destiempo (y tienen hoy día velocidades diferentes), las del transporte aéreo en 1992-1996 y las del turismo recién en 2005 con la primer Política Sectorial del Turismo (Díaz Olariaga, 2015). Sin embargo, esta situación está en vías de homogenización gracias a las directrices emanadas de los diferentes planes sectoriales de turismo, en curso el Plan Sectorial de Turismo 2018-2022 (MinCIT, 2018).

\section{Bibliografía}

ACI 2019. Annual World Airport Traffic Report. Montreal: Airport Council International.

Aerocivil 2020. Estadísticas de las Actividades Aeronáuticas. http://www.aerocivil.gov.co

Aerocivil 2019. Plan Estratégico Institucional 2019-2022. Bogotá: Aeronáutica Civil de Colombia.

Alsumairi, M. y Tsui, K.W.H. 2017. "A case study: The impact of low-cost carriers on inbound tourism of Saudi Arabia". Journal of Air Transport Management, 62, 129-145.

ANI 2019. Plan de Transporte Multimodal. https://www.ani.gov.co/planes/plan-maestro-de-transporte-intermodal-22006

Barrett, S. 2008. "The emergence of the low cost carrier sector". In: Graham, A.; Papatheodorou, A. \& Forsyth, P. (Eds.), Readings in Aviation and Tourism: Implications for Leisure Travel. Hampshire: Ashgate Publishing.

Belobaba, P.; Odoni, A. y Barnhart, C. 2009. The global airline industry. Chichester: John Wiley \& Sons.

Bieger, T. y Wittmer, A. 2206. "Air transport and tourism e perspectives and challenges for destinations, airlines and governments". Journal of Air Transport Management, 12(1), 40-46.

Bosch, A. y García Montalvo, J. 2003. "Free and Nondiscriminatory Access to Airports: A Proposal for Latin America". Working paper. Washington, D.C.: IADB.

Burghouwt, G. y de Wit, J.G. 2015. "In the wake of liberalisation: long-term developments in the EU air transport market". Transport Policy, 43, 104-113.

CAF 2006. Estudio Analítico sobre la Integración del Transporte Aéreo en América del Sur. Caracas: Corporación Andina de Fomento.

Carvallo, C. 2008. Experiencia chilena en concesiones aeroportuarias. Santiago de Chile: Ministerio de Obras Públicas.

Chung, J.Y. y Whang, T. 2011. "The impact of low cost carriers on Korean Island tourism". Journal of Transport Geography, 19(6), 1335-1340.

CEPAL 2017. "Transporte aéreo como motor del desarrollo sostenible en América Latina y el Caribe: retos y propuestas de política”. Boletín FAL (CEPAL), $\mathrm{N}^{\circ} 357$.

Costa, T.F.G.; Lohmann, G. y Oliveira, A.V.M. 2010. "A model to identify airport hubs and their importance to tourism in Brazil". Research in Transportation Economics, 26, 3-11.

DANE 2006. Anuario estadístico de movimientos internacionales-2006. Bogotá: Departamento Administrativo Nacional de Estadística (DANE).

Díaz Olariaga, O. y Pulido, L. 2019. "Measurement of airport efficiency. The case of Colombia". Transport and Telecommunication, 20(1), 40-51.

Díaz Olariaga, O. y Zea, J.F. 2018. "Influence of the liberalization of the air transport industry on configuration of the traffic in the airport network". Transportation Research Procedia, 33, 43-50. 
Díaz Olariaga, O.; Bolívar, N.; Gutiérrez, R.; Rico Galeana, O. 2018. "Gravitational analysis of the air transport network. Application to the case of Colombia". Transportation Research Procedia, 33, 51-58.

Díaz Olariaga, O.; Carvajal, A. 2017. "Geografía del transporte de pasajeros y conectividad aérea en Colombia”. VI Congreso de Geografía de las Américas. 11-13 Oct. 2017, Tacna, Perú.

Díaz Olariaga, O. 2017a. "Análisis de la privatización, regulación y operación aeroportuaria". XII Congreso Colombiano de Transporte y Tránsito. 24-26 de Julio de 2017, Bogotá, Colombia.

Díaz Olariaga, O. 2017b. "Políticas de privatización de aeropuertos. El caso de Colombia". Documentos y Aportes en Administración Pública y Gestión Estatal, 29, 7-35.

Díaz Olariaga, O.; Girón Amaya, E. y Mora-Camino, F. 2017. "Pronóstico de la demanda de pasajeros en aeropuertos privatizados". VI Congreso Internacional de la Red Iberoamericana de Investigación en Transporte Aéreo. 10-12 octubre 2017, Santiago de Chile.

Díaz Olariaga, O. 2016a. "Análisis del desarrollo reciente del transporte aéreo en Colombia". Revista Transporte y Territorio, 14, 122-143.

Díaz Olariaga, O. 2016b. "Análisis de la evolución de las políticas públicas y de regulación en la industria aeroportuaria en Colombia". Documentos y Aportes en Administración Pública y Gestión Estatal, 26, 7-42.

Díaz Olariaga, O.; López, A.L. 2016. “Comportamiento e interrelación del turismo y el transporte aéreo en Colombia". Estudios y Perspectivas en Turismo, 25(1), 36-56.

Díaz Olariaga, O.; Carvajal, A.F. 2016. "Efectos de la liberalización en la geografía del transporte aéreo en Colombia”. Cuadernos Geográficos, 55(2), 344-364.

Díaz Olariaga, O. 2015. "Análisis de la aplicación de políticas públicas en el sector turismo. El caso de Colombia". Gestión y Análisis de Políticas Públicas, 14, 115-130.

Díaz Olariaga, O. y ÁVILA, J. 2015. "Evolution of the airport and air transport industry in Colombia and its impact on the economy". Journal of Airline and Airport Management, 5(1), 39-66.

Dimitriou, D.; Mourmouris, C. y Sartzetaki, F. 2017. "Quantification of the air transport industry socio-economic impact on regions heavily depended on tourism". Transportation Research Procedia, $25,5242-5254$.

DNP 2019. Plan Nacional de Desarrollo 2018-2022. Bogotá: Departamento Nacional de Planeación.

DNP 2018. "Planeación en el transporte aéreo colombiano". II Foro Sector Aéreo 2030. 5 de julio 2018, Bogotá. Colombia.

DNP 2014. Plan Nacional de Desarrollo 2014-2018. Bogotá: Departamento Nacional de Planeación.

DNP 1994. Reordenamiento institucional y plan de expansión del sistema aeroportuario - Documento CONPES 2727. Bogotá: Departamento Nacional de Planeación.

Dobruszkes, F. y Mondou, V. 2013. "Aviation liberalization as a means to promote international tourism: The EU-Morocco case". Journal of Air Transport Management, 29, 23-34.

Dobruszkes, F.; Mondou, V. y Ghedira, A. 2016. "Assessing the impacts of aviation liberalisation on tourism: some methodological considerations derived from the Moroccan and Tunisian cases". Journal of Transport Geography, 50, 115-127.

Dobruszkes, F. 2009. "Does liberalization of air transport imply increasing competition? Lessons from the European case". Transport Policy, 16(1), 29-39.

Doganis, R. 2006. The Airline Business. London: Routledge.

Duval, D.T. 2008. "Regulation, competition and the politics of air access across the Pacific". Journal of Air Transport Management, 14(5), 237-242.

Duval, D.T. 2013. "Critical Issues in Air Transport and Tourism”. Tourism Geographies, 15(3), 494-510.

Espirito Santo, R.A.; Correia, F.C. y Palhares, G.L. 2001. "Airport Privatization in Brazil: Questions and Answers". Proceedings of the 36th Canadian Transportation Research Forum (CTRF), Annual Conference. Vancouver, Canada.

Espirito Santo, R.A. 2013. "Airport privatization and Business Models: What Brazil has and what Brazil Needs". VI WALA Conference, Montreal, Canada.

Fedesarrollo 2016. Competitividad en el transporte aéreo en Colombia. Bogotá: Fedesarrollo.

Forsyth, P. 2006. "Martin Kunz Memorial Lecture. Tourism benefits and aviation policy". Journal of Air Transport Management, 12, 3-13.

Forsyth, P. 2010. "Tourism and aviation policy: exploring the links". In: Graham, A.; Papatheodouru, A. \& Forsyth, P. (Eds.), Aviation and Tourism: Implications for Leisure Travel. Hampshire: Ashgate Publishing.

Fu, X. y Oum, T.H. 2014. "Air transport liberalization and its effects on airline competition and traffic growth - an overview". Advances in Airline Economics, 4, 11-44. 
Fu, X.; Oum, T.H.; Chen, R. y Lei, Z. 2015. "Dominant carrier performance and international liberalization - the case of Northeast Asia". Transport Policy, 43, 61-75.

Galli, P.; Fraga, C. y de Sequeira Santos, M.P. 2016. "Gravitational force exerted by Brazilian tourist destinations on foreign air travelers". Journal of Air Transport Management, 55, 76-83.

Graham, A.; Papatheodorou, A. y Forsyth, P. 2008. Aviation and Tourism. Burlington: Ashgate Publishing Company.

Graham, A. y Dobruszkes, F. 2019. Air Transport - A Tourism Perspective. Amsterdam: Elsevier.

IADB (2007). Estudio de Integración del Transporte Aéreo en Sudamérica. Washington, D.C.: Inter-American Development Bank.

IATA 2019. El valor de la aviación en Colombia. Bogotá: IATA Economics.

Levine, M.E. 2006. "Why weren't the airlines reregulated?". Yale Journal on Regulation, 23(2), 269-297.

Lieshout, R.; Malighetti, P.; Redondi, R. y Burghouwt, G. 2016. "The competitive landscape of air transport in Europe". Journal of Transport Geography, 50, 68-82.

Lipovich, G. 2008. "The privatization of Argentine airports". Journal of Air Transport Management, 14(1), 8-15.

Menchero, M. 2018. "Colombia en posconflicto: ¿turismo para la paz o paz para el turismo?". Araucaria, Revista Iberoamericana de Filosofía, Política y Humanidades, 39, 415-438.

Mendiola, A.; Arévalo, G.; Maratuech, P.; Pérez, J. y Valencia, J.C. 2011. Concesión del aeropuerto Jorge Chávez: evaluación del valor generado. Lima: ESAN Ediciones.

MinCIT 2020. Ministerio de Industria, comercio y Turismo de Colombia. Informes de Turismo. http:// www.mincit.gov.co/estudios-economicos/estadisticas-e-informes/informes-de-turismo

MinCIT 2018. Plan Sectorial de Turismo 2018-2022. Bogotá: Ministerio de Comercio, Industria y Turismo de Colombia.

Miranda, A. y Gutierrez, J. 2008. "El derecho de la competencia en el sector aeronáutico colombiano". Revista de Derecho de la Competencia, 4(4), 287-403.

Morrison, S. y Winston, C. 1995. The Evolution of the Airline Industry. Washington, D.C.: Brookings Institution.

OACI 2006. Convenio sobre Aviación Civil lnternacional. Montreal: OACI.

ORE - Oficina de Regulación Económica 2011. Seguimiento y evaluación de impacto de la política aerocomercial internacional de pasajeros y carga. Bogotá: ORE.

ORE - Oficina de Regulación Económica 2009. Recomendaciones sobre lineamientos de política aerocomercial internacional de pasajeros y carga. Bogotá: ORE.

Oum, T.H. y Lee, Y.H. 2002. "The Northeast Asian air transport network: is there a possibility of creating open skies in the region?". Journal of Air Transport Management, 8(5), 325-337.

Papatheodorou, A. 2010. "The impact of civil aviation regimes on leisure market". In: Graham, A.; Papatheodorou, A. \& Forsyth, P. (Eds.), Aviation and Tourism: Implications for Leisure Travel. Hampshire: Ashgate Publishing.

Rico Galeana, O. 2008. "The privatization of Mexican airports". Journal of Air Transport Management, 14(6), 320-323.

Sengür, F.K.; Hemdil, O.; Ajanovic, E.; Caber, M. y Yilmaz, Y. 2014. "International air transport and inbound tourism interaction: the case of Istanbul". International Antalya Hospitality Tourism and Travel Research Conference. Antalya, 9-12 December 2014.

Serebrisky, T. 2012. Airport Economics in Latin America and the Caribbean. Washington D.C.: The World Bank.

Spasojevic, B.; Lohmann, G. y Scott, N. 2017. "Air transport and tourism - a systematic literature review (2000-2014)". Current Issues in Tourism, 1-23.

Wittmer, A.; Bieger, T. y Muller, R. 2011. Aviation Systems. Heidelberg: Springer.

Warnock-Smith, D. y Morrell, P. 2008. "Air transport liberalisation and traffic growth in tourism-dependent economies: A case-history of some US-Caribbean markets". Journal of Air Transport Management, 14, 82-91.

Warnock-Smith, D. y O'connell, J.F. 2011. "The impact of air policy on incoming tourist traffic: the contrasting cases of the Caribbean Community and the Middle-East". Journal of Transport Geography, 19, 265-274.

Winston, C. y Peltzman, S. 2000. Deregulation of Network Industries: What's Next?. Washington, D.C.: AEI Brookings Joint Center for Regulatory Studies.

Wu, C. 2016. "How aviation deregulation promotes international tourism in Northeast Asia: A case of the charter market in Japan”. Journal of Air Transport Management, 57, 260-271. 
Wu, C.; Jiang, Q. y Yang, H. 2018. "Changes in cross-strait aviation policies and their impact on tourism flows since 2009". Transport Policy, 63, 61-72.

Yarde, K. y Jonsson, C. 2016. "Implications for CARICOM member states in the search for a "liberally controlled' air transport market: The case of regional tourism to Barbados". Journal of Air Transport Management, 53, 12-22.

Yepes, T.; Ramirez, J.; Villar, L. y Aguilar, J. 2013. Infraestructura de transporte en Colombia. Cuadernos Fedesarrollo 46. Bogotá: Fedesarrollo.

Zajac, G. 2016. "The role of air transport in the development of international tourism". Journal of International Trade, Logistics and Law, 2(1), 1-8.

Zhang, Y. y Findlay, C. 2014. "Air transport policy and its impacts on passenger traffic and tourist flows". Journal of Air Transport Management, 34, 42-48.

Zhang, Y. y Round, D.K. 2008. "China's airline deregulation since 1997 and the driving forces behind the 2002 airline consolidations". Journal of Air Transport Management, 14(3), 130-142. 